\title{
A prospective feasibility study of one-year administration of adjuvant S-1 therapy for resected biliary tract cancer in a multi- institutional trial (Tokyo Study Group for Biliary Cancer: TOSBIC01)
}

Osamu Itano ${ }^{1,2^{*}+}$, Yusuke Takemura $^{1+}$, Norihiro Kishida ${ }^{3}$, Eiji Tamagawa ${ }^{4}$, Hiroharu Shinozaki ${ }^{5}$, Ken Ikeda ${ }^{6}$, Hidejiro Urakami ${ }^{7}$, Shigenori $\mathrm{Ei}^{8}$, Shigeo Hayatsu ${ }^{9}$, Keiichi Suzuki ${ }^{10}$, Tadayuki Sakuragawa ${ }^{11}$, Masatsugu Ishii ${ }^{12}$, Masaya Shito ${ }^{13}$, Koichi Aiura ${ }^{13}$, Hiroto Fujisaki ${ }^{14}$, Kiminori Takano ${ }^{14}$, Junichi Matsui ${ }^{15}$, Takuya Minagawa ${ }^{16}$, Masahiro Shinoda', Minoru Kitago ${ }^{1}$, Yuta Abe ${ }^{1}$, Hiroshi Yagi ${ }^{1}$, Go Oshima ${ }^{1}$, Shutaro Hori ${ }^{1}$ and Yuko Kitagawa ${ }^{1}$

\begin{abstract}
Background: Although surgery is the definitive curative treatment for biliary tract cancer (BTC), outcomes after surgery alone have not been satisfactory. Adjuvant therapy with S-1 may improve survival in patients with BTC. This study examined the safety and efficacy of 1 year adjuvant S-1 therapy for BTC in a multi-institutional trial.

Methods: The inclusion criteria were as follows: histologically proven BTC, Eastern Cooperative Oncology Group (ECOG) performance status 0 or 1, R0 or R1 surgery performed, cancer classified as Stage IB to III. Within 10 weeks post-surgery, a 42-day cycle of treatment with S-1 ( $80 \mathrm{mg} / \mathrm{m}^{2} /$ day orally twice daily on days $1-28$ of each cycle) was initiated and continued up to 1 year post surgery. The primary endpoint was adjuvant therapy completion rate. The secondary endpoints were toxicities, disease-free survival (DFS), and overall survival (OS).

Results: Forty-six patients met the inclusion criteria of whom 19 had extrahepatic cholangiocarcinoma, 10 had gallbladder carcinoma, 9 had ampullary carcinoma, and 8 had intrahepatic cholangiocarcinoma. Overall, 25 patients completed adjuvant chemotherapy, with a $54.3 \%$ completion rate while the completion rate without recurrence during the 1 year administration was 62.5\%. Seven patients (15\%) experienced adverse events (grade 3/4). The median number of courses administered was 7.5. Thirteen patients needed dose reduction or temporary therapy withdrawal. OS and DFS rates at 1/2 years were $91.2 / 80.0 \%$ and $84.3 / 77.2 \%$, respectively. Among patients who were administered more than 3 courses of S-1, only one patient discontinued because of adverse events.

(Continued on next page)
\end{abstract}

\footnotetext{
* Correspondence: laplivertiger@gmail.com

${ }^{\dagger}$ Osamu Itano and Yusuke Takemura contributed equally to this work.

'Department of Surgery, Keio University School of Medicine, Tokyo, Japan

2 Department of Hepato-Biliary-Pancreatic and Gastrointestinal Surgery,

International University of Health and Welfare School of Medicine, 4-3,

Kozunomori, Narita-shi, Chiba 286-8686, Japan

Full list of author information is available at the end of the article
}

(c) The Author(s). 2020 Open Access This article is licensed under a Creative Commons Attribution 4.0 International License, which permits use, sharing, adaptation, distribution and reproduction in any medium or format, as long as you give appropriate credit to the original author(s) and the source, provide a link to the Creative Commons licence, and indicate if changes were made. The images or other third party material in this article are included in the article's Creative Commons licence, unless indicated otherwise in a credit line to the material. If material is not included in the article's Creative Commons licence and your intended use is not permitted by statutory regulation or exceeds the permitted use, you will need to obtain permission directly from the copyright holder. To view a copy of this licence, visit http://creativecommons.org/licenses/by/4.0/. The Creative Commons Public Domain Dedication waiver (http://creativecommons.org/publicdomain/zero/1.0/) applies to the data made available in this article, unless otherwise stated in a credit line to the data. 
(Continued from previous page)

Conclusions: One-year administration of adjuvant S-1 therapy for resected BTC was feasible and may be a promising treatment for those with resected BTC. Now, a randomized trial to determine the optimal duration of S-1 is ongoing.

Trial registration: UMIN-CTR, UMIN000009029. Registered 5 October 2012-Retrospectively registered, https://upload. umin.ac.jp/cgi-open-bin/ctr_e/ctr_view.cgi?recptno=R000009347

Keywords: Biliary tract cancer, Adjuvant chemotherapy, 1-year administration of S-1, Feasibility study

\section{Background}

Biliary tract cancer (BTC) includes intrahepatic cholangiocarcinoma, perihilar cholangiocarcinoma, distal cholangiocarcinoma, gallbladder carcinoma, and ampulla of Vater carcinoma. BTC is well-known as one of the most dismal prognostic malignant diseases and its incidence has been increasing [1-3]. Although surgical resection may provide curative treatment, the risk of recurrence is quite high and the reported prognosis of patients with resected advanced BTC is relatively low $[4,5]$. Therefore, development of effective perioperative adjuvant therapy is currently being investigated. A meta-analysis series has shown the potential benefit of adjuvant chemotherapy, especially for patients with node-positive resected biliary tract cancer [6]. Despite the potential benefits, no prior randomized control trial (RCT) proved the positive effect of postoperative adjuvant chemotherapy in patients with BTC [7, 8]. Recently, a RCT assessing a 6-month administration of capecitabine for adjuvant therapy for BTC demonstrated improvements in survival [9]; however, the optimal adjuvant chemotherapy regimen for resected BTC has not yet been standardized.

$\mathrm{S}-1$ is well-known as an oral anticancer drug consisting of tegafur, 5-chloro-2, 4-dihydroxypyridine and potassium oxonate. S-1 has already been established as a standardized adjuvant therapy for patients with gastric and pancreatic cancer $[10,11]$. Regarding BTC, a phase II trial evaluating unresectable and recurrent cholangiocarcinoma indicated that S-1 had a 35\% response rate, and adverse events were also relatively controlled [12]. One prospective phase II trial comparing the efficacy of 6-month administration of S-1 and gemcitabine for adjuvant therapy after curative resection of BTC also showed better prognosis in the S-1 group [13]. Moreover, in Japan, the efficacy of 6-month administration of S-1 for postoperative BTC is currently being investigated in the large-scale phase III ASCOT trial [14]. Thus, S-1 is expected to become a standard treatment in adjuvant therapy for resected BTC.

However, the duration of administration was not verified. One non-inferiority study comparing 1-year administration of S-1 with 6-month administration of S1 for adjuvant therapy of resected gastric cancer was performed; eventually the study was censored because the 1-year administration group had significantly better prognosis in the interim analysis [15]. 1-year administration is still the standard for the treatment of gastric cancer. Therefore, we hypothesized that 1-year administration of S-1 would improve the prognosis, more than 6-month administration for resected BTC. Although the pilot ASCOT trial showed a high completion rate (75.8\%) with 6-month administration of S-1 for BTC adjuvant therapy [16], there has been no conclusive evidence on the feasibility of 1-year administration of S-1. Thus, we planned a phase 2 study to investigate the feasibility of 1 -year administration of S-1.

\section{Methods \\ Eligibility criteria}

Patients who underwent radical surgery for BTC and who were diagnosed pathologically were eligible if they met the following inclusion criteria: those with BTCs classified into either intrahepatic, hilar/perihilar, or extrahepatic cholangiocarcinoma, gallbladder cancer, or ampullary of Vater carcinomas according to the WHO classification 2010 [17]; Moreover, patients were included, if the eligible pathological stage ranged from Stage IB to Stage III according to the 6th edition of the UICC/AJCC staging system [18] without macroscopic residual tumors; if no distant metastases and no peritoneal dissemination was observed; if no prior chemotherapy or radiation for BTC was administered; patients who were able to start chemotherapy within 10 weeks after surgery; age $\geq 20$ years; Eastern Cooperative Oncology Group Performance Status (ECOG-PS) 0 or 1; adequate oral intake; adequate bone marrow function (white blood cells $\geq 3500 / \mathrm{mm}^{3}$, neutrophils $\geq 2000 / \mathrm{mm}^{3}$, platelet $\geq 100,000 / \mathrm{mm}^{3}$, hemoglobin $\geq 9.0 \mathrm{~g} / \mathrm{dL}$ ), adequate liver function [aspartate aminotransferase (AST) $\leq 100 \mathrm{IU} / \mathrm{L}$ (or $150 \mathrm{IU} / \mathrm{L}$ under biliary drainage), alanine aminotransferase (ALT) $\leq 100 \mathrm{IU} / \mathrm{L}$ (or $150 \mathrm{IU} / \mathrm{L}$ under biliary drainage)] serum total bilirubin $\leq 2.0 \mathrm{mg} / \mathrm{dL}$ (or $\leq 3.0 \mathrm{mg} / \mathrm{dL}$ under biliary drainage), adequate renal function [serum creatinine $\leq 1.2 \mathrm{mg} / \mathrm{dL}$ and creatinine clearance or estimated glomerular filtration rate (GFR) by Cockcroft-Gault formula $\geq 60$ $\mathrm{mL} / \mathrm{min}]$, and serum albumin $\geq 3.0 \mathrm{~g} / \mathrm{dL}$; normal EKG findings within 28 days before registration; and written informed consent.

The exclusion criteria were as follows: previous history of S-1 administration; uncontrollable diarrhea; history of flucytosine, phenytoin, or warfarin potassium treatments; 
accumulated pleural effusion or ascites; presence of active infection without viral hepatitis; presence of other cancer except carcinoma in situ within 3 years; severe organ dysfunction (such as heart failure, renal failure, liver failure, intestinal paralysis, uncontrollable diabetes mellitus); presence of pulmonary fibrosis or interstitial pneumonitis; presence of severe mental disorder; presence of severe drug allergy; transfusion within 14 days before registration; women who were pregnant or nursing; women who may have been pregnant or were willing/trying to get pregnant; and unsuitable candidates for this study as judged by the physician.

\section{Study design (single-arm, non-randomized, open, historical control)}

This study was designed by the Keio Surgery Research Network (KSRN) and was conducted at the Keio University Hospital. This study was registered with University Hospital Medical Information Network (UMIN) center (unique trial number: UMIN000009029). Patient registration and data management were conducted at an independent center at Keio University School of Medicine. All laboratory tests required to assess eligibility were completed within 28 days before the start of protocol treatment.

\section{Treatment schedule}

S-1 (tegafur, gimeracil, oteracil potassium; Taiho Pharmaceutical, Tokyo, Japan) was administered within 10 weeks after the surgery. An oral dose of $80 \mathrm{mg} / \mathrm{m}^{2} \mathrm{~S}-1$ was given every day on days 1 to 28 of a 6-week cycle for a year. The total dose was based on the patient's body surface area as follows: < $1.25 \mathrm{~m}^{2}, 80 \mathrm{mg} ; 1.25-1.5 \mathrm{~m}^{2}, 100 \mathrm{mg} ;>1.5 \mathrm{~m}^{2}$, $120 \mathrm{mg}$. After a-year of chemotherapy, additional chemotherapy was not given unless the patient was diagnosed with recurrence.

The protocol permitted dose modifications and cycle interruptions were as follows: white blood cells <2000/ $\mathrm{mm}^{3}$, neutrophils $<1000 / \mathrm{mm}^{3}$, platelet $<75,000 / \mathrm{mm}^{3}$, hemoglobin $<8.0 \mathrm{~g} / \mathrm{dL}$, adequate liver function (AST > $150 \mathrm{IU} / \mathrm{L}, \mathrm{ALT}>150 \mathrm{IU} / \mathrm{L})$, serum total bilirubin $>3.0$ $\mathrm{mg} / \mathrm{dL}$, serum creatinine $>1.5 \mathrm{mg} / \mathrm{dL}$, and adverse events associated with gastrointestinal symptom $\geq$ Grade 3 . In cases for which the S-1 dose was reduced, the dose was decreased by $20 \mathrm{mg} /$ body weight while maintaining a minimum dose of $60 \mathrm{mg} /$ body weight, and it was not subsequently increased for any reason. When dose interruptions were prolonged for longer than 4 weeks or if dose reductions below $60 \mathrm{mg} / \mathrm{m}^{2}$ were required, the patient was considered for medication discontinuation. Patients had the option to withdraw from the trial or during follow-up at any stage. Furthermore, criteria for treatment discontinuation included factors such as the physician's decision, recurrence, and development of other cancers.

\section{Follow up after surgery}

Postoperative follow-up CT scanning were performed at $3,6,12$ months for the first year and every 6 months following that. Tumor marker tests were conducted every 3 months for 2 years.

\section{Evaluation of toxicity}

Toxicity was categorized according to the Common Terminology Criteria for Adverse Events, version 4.0. Toxicity was recorded during treatment continuously.

\section{Outcomes}

The primary outcome was completion rate at 1 year after first administration of S-1. Secondary outcomes included relative dose intensity (RDI), toxicity, overall survival rate, and disease-free survival rate at 2 years, which was defined as the time from registration until the event. RDI was defined as the proportion of actual dose intensity received to the planned dose intensity.

The expected treatment completion rate was set at $50 \%$ based on the data of the ACTS-GC trial, of which completion rate was $65.8 \%$ [10]. It was expected that the completion rate would be lower after major hepatobiliary and pancreatic surgeries than after gastric cancer surgery due to increased adverse events and recurrence. The sample size was calculated as 43 patients with a 95\% confidence interval for the completion rate of treatment within $30 \%$. Therefore, the target number of patients was set to be 50 for possible ineligible patients.

\section{Statistical analyses}

Data are presented as median (range) or number of patients (\%). Intergroup comparisons were performed using the Mann-Whitney $U$ test and chi-square test for continuous and categorical variables, respectively. To identify risk factors for early discontinuation (defined as discontinuation within 2 courses), we performed univariate and multivariate logistic regression analyses. Variables with $P$ values $<0.10$ in the univariate analysis were included in the multivariate logistic regression analysis. $P<0.05$ was considered statistically significant. The SPSS 25.0 statistical software (SPSS, Inc., Chicago, IL, USA) was used to perform all the statistical calculations.

\section{Results}

\section{Patient characteristics}

Between June 2011 and December 2014, 50 patients were enrolled in this study. A total of 46 patients were eligible; patient characteristics are summarized in Table 1. The median age was 68.5 years (range, $39-84$ years). Nineteen (41\%) patients had extrahepatic cholangiocarcinoma, 8 (17\%) patients had intrahepatic cholangiocarcinoma, 10 (22\%) had gallbladder carcinoma and 9 (20\%) had ampulla of Vater carcinoma. Surgical procedures consisted of 25 
Table 1 Patient characteristics $(n=46)$

\begin{tabular}{|c|c|c|}
\hline \multicolumn{2}{|l|}{ Variables } & $\begin{array}{l}\mathrm{n}(\%) \text { or median } \\
\text { (range) }\end{array}$ \\
\hline \multicolumn{2}{|l|}{ Male: Female } & $28(61 \%) / 18(39 \%)$ \\
\hline \multicolumn{2}{|l|}{ Age, years } & $68.5(39-84)$ \\
\hline \multirow[t]{2}{*}{ ECOG-PS } & 0 & $39(85 \%)$ \\
\hline & 1 & $7(15 \%)$ \\
\hline \multirow[t]{4}{*}{ Primary disease } & Extrahepatic & $19(41 \%)$ \\
\hline & Intrahepatic & $8(17 \%)$ \\
\hline & Gallbladder & $10(22 \%)$ \\
\hline & Ampulla of Vater & $9(20 \%)$ \\
\hline \multirow{3}{*}{$\begin{array}{l}\text { Pathologically stage } \\
\text { (UICC) }\end{array}$} & 1 & $10(22 \%)$ \\
\hline & $\|$ & $29(63 \%)$ \\
\hline & III & $7(15 \%)$ \\
\hline \multirow[t]{4}{*}{ Surgical procedure } & Pancreatoduodenectomy & $25(54 \%)$ \\
\hline & $\begin{array}{l}\text { Hepatectomy } \\
\text { (without bile duct resection) }\end{array}$ & $6(13 \%)$ \\
\hline & $\begin{array}{l}\text { Hepatectomy } \\
\text { (with bile duct resection) }\end{array}$ & $6(13 \%)$ \\
\hline & Extended cholecystectomy & $9(20 \%)$ \\
\hline \multirow{4}{*}{$\begin{array}{l}\text { Morbidity } \\
\text { (Clavien-Dindo } \geq 3 \text { ) }\end{array}$} & Total & $10(22 \%)$ \\
\hline & Pancreatic fistula & $8(17 \%)$ \\
\hline & Liver abcess & $1(2 \%)$ \\
\hline & Intraabdominal abcess & $1(2 \%)$ \\
\hline \multirow[t]{2}{*}{ Residual tumor } & 0 & $43(94 \%)$ \\
\hline & 1 & $3(7 \%)$ \\
\hline $\begin{array}{l}\text { Lymph node } \\
\text { metastasis }\end{array}$ & Positive & $20(46 \%)$ \\
\hline \multicolumn{2}{|l|}{ CEA, ng/dL } & $1.8(0.1-54.0)$ \\
\hline \multicolumn{2}{|l|}{ CA19-9, ng/dL } & $17.0(1.0-3197)$ \\
\hline
\end{tabular}

Abbreviations: ECOG-PS Eastern Cooperative Oncology Group Performance Status, CEA carcinoembryonic antigen, CA19-9 carbohydrate antigen 19-9

(54\%) pancreatoduodenectomies, 6 (13\%) hepatectomies without bile duct resection, 6 (13\%) hepatectomies with bile duct resection, and 9 (20\%) extended cholecystectomies. Forty-three $(94 \%)$ patients achieved R0 resection and 20 (46\%) had regional lymph node metastases.

\section{Feasibility analysis (Tables 2, 3, Supplementary Table 1)}

Table 2 shows the main results. The completion rate for all patients was $54.3 \%$ while the completion rate without recurrence during the 1 year administration was $62.5 \%$. The median relative dose intensity was $62.9 \%$. Of 25 patients with completion, 13 needed dose reduction or temporary therapy withdrawal, 13 patients withdrew from S-1 administration owing to adverse events and 8
Table 2 Main outcomes

\begin{tabular}{ll}
\hline & $\begin{array}{l}\mathrm{n}(\%) \text { or median } \\
\text { (range) }\end{array}$ \\
\hline Days from operation to administration, day & $54(31-70)$ \\
Completion rate, \% & $25(54.3 \%)$ \\
Completion rate without recurrence, \% & $25(62.5 \%)$ \\
Reson of cessation $(n=21)$ & \\
Recurrence & $6(28.6 \%)$ \\
Adverse event & $13(61.9 \%)$ \\
Gastrointestinal & 8 \\
Myelosuppression & 2 \\
Stomatitis & 1 \\
Cholangitis & 1 \\
Chest pain & 1 \\
Others & $2(9.5 \%)$ \\
Traffic accident & 1 \\
House-moving & 1 \\
Relative dose intensity, \% & $62.9(0.7-100)$ \\
\hline
\end{tabular}

of these discontinued cases were due to gastrointestinal adverse events. The reason for discontinuation is summarized in Table 3. Nine cases discontinued because of adverse events at the first course and 3 cases discontinued at the second course. Only one case withdrew after receiving 2 courses due to adverse events. We analyzed the risk factors for early discontinuation, which was defined as discontinuation within 2 courses due to adverse events (Supplementary Table 1). We divided the patients into two groups: the early discontinuation group $(n=12)$ and the remaining patients $(n=34)$. Multivariate analysis identified the age of patients ( $\geq 69$ years old) as an independent risk factor of early discontinuation (HR: 6.5, 95\% confidence interval $(\mathrm{CI}): 1.2-40.0, P=0.03)$.

\section{Completion rate by primary disease and surgical procedures (Table 4)}

Completion rate for all patients and those without recurrence based on their primary disease and surgical procedures are shown in Table 4. The completion rate excluding recurrent cases ranged from 60.0 to $66.7 \%$ by the type of surgical procedures.

\section{Adverse events (Table 5)}

Adverse events are shown in Table 5. In total, 41 (89\%) patients suffered adverse events (any grade). Hematological events were most common in all grade adverse events. Overall, 7 (15\%) patients suffered severe adverse events at grade 3 or more. Gastrointestinal events such as anorexia or diarrhea were more frequent than hematologic events or other events. 
Table 3 The reason of discontinuation

\begin{tabular}{lllll}
\hline $\begin{array}{l}\text { Course } \\
\text { No. }\end{array}$ & $\begin{array}{l}\text { No. of } \\
\text { discontinued } \\
\text { patients }\end{array}$ & Reason of discontinuation & Recurrence & Other \\
\cline { 4 - 5 } & 9 & Adverse event & - & - \\
& & $\begin{array}{l}\text { Gystrointestinal, 6 } \\
\text { Chest pain, 1 }\end{array}$ & & - \\
2 & 4 & Gastrointestinal, 2 Myelosuppression, 1 & 1 & - \\
3 & 1 & - & 1 & - \\
4 & 2 & - & 2 & - \\
5 & 1 & - & - & - \\
6 & 1 & - & - & Traffic accident, 1 \\
7 & 1 & - & House-moving, 1 \\
8 & 2 & Stomatitis 1 & -
\end{tabular}

\section{Long-term outcome (Fig. 1)}

The median follow-up time for all patients in this study was 38.4 months (range, 7.5-56.8 months). The 2-year OS and DFS were $80.0 \%$ (95\% CI, 68.2-91.8\%) and $77.2 \%$ (95\% CI, 64.7-89.7\%) and, respectively (Fig. 1). Eight $(60 \%)$ of 14 patients who had recurrence in this study period developed recurrence in the liver. The other recurrence sites were as follows: lymph nodes, 5; lung, 3; local recurrence, 2; peritoneal dissemination, 2 and bone, 2 .

\section{Discussion}

In this study, we evaluated the feasibility of adjuvant chemotherapy by assessing the outcomes of 1-year administration of S-1 for resected BTC. Our prospective phase II study demonstrated that a completion rate without recurrence during the 1-year administration of S-1 was over $60 \%$ and the rate was $50 \%$ or more regardless of the surgical procedures or primary disease. The most frequent reason for withdrawal was gastrointestinal adverse events occurring early in the treatment course.

The completion rate in this study was $54.3 \%$ (when recurrence cases were excluded, the rate was $62.5 \%$ ). Previous reports regarding adjuvant chemotherapy for resected gastric cancer showed that 1-year administration of S-1 was tolerable in $48.6-65.8 \%$ of patients (in those without recurrence, 60.7-69.1\%) [10, 19]. Several studies have evaluated the 6-month administration of S1 in BTC. One reported the completion rate was $51.4 \%$ (the rate for those without recurrence was not available) for BTC after major hepatectomy [13] and the other reported a complete rate of $75.8 \%$ (the rate for those without recurrence, 86.0\%) [16]. Regarding other types of cancer, a 6-month administration of S-1 was completed in $76.5 \%$ of cases (rate for non-recurrence, not

Table 4 The completion rate by primary disease and surgical procedure

\begin{tabular}{|c|c|c|c|c|c|}
\hline & \multicolumn{4}{|c|}{ Primary disease } & \multirow[t]{2}{*}{ Total } \\
\hline & Extrahepatic & Intrahepatic & Gallbladder & Ampulla of Vater & \\
\hline \multicolumn{6}{|l|}{ (a) Full analysis set $(n=46)$} \\
\hline Pancreatoduodenectomy & $6 / 15$ (40.0\%) & - & $1 / 1(100 \%)$ & 5/9 (55.6\%) & $12 / 25(48.0 \%)$ \\
\hline Hepatectomy without bile duct resection & - & $4 / 6(66.7 \%)$ & - & - & $4 / 6(66.7 \%)$ \\
\hline Hepatectomy with bile duct resection & 2/4 (50.0\%) & $1 / 2(50.0 \%)$ & - & - & $3 / 6(50.0 \%)$ \\
\hline Extended cholecystectomy & - & - & 6/9 (66.7\%) & - & 6/9 (66.7\%) \\
\hline Total & $8 / 19(42.1 \%)$ & $5 / 8(62.5 \%)$ & 7/10 (70.0\%) & 5/9 (55.6\%) & $25 / 46(54.3 \%)$ \\
\hline \multicolumn{6}{|l|}{ (b) Cases excluding recurrent cases $(n=40)$} \\
\hline Pancreatoduodenectomy & 6/13 (46.2\%) & - & $1 / 1(100 \%)$ & 5/6 (83.3\%) & $12 / 20(60.0 \%)$ \\
\hline Hepatectomy without bile duct resection & - & 4/6 (66.7\%) & & - & $4 / 6(66.7 \%)$ \\
\hline Hepatectomy with bile duct resection & $2 / 4(50.0 \%)$ & $1 / 1(100 \%)$ & - & - & $3 / 5(60.0 \%)$ \\
\hline Extended cholecystectomy & - & - & 6/9 (66.7\%) & - & 6/9 (66.7\%) \\
\hline Total & $8 / 17$ (47.1\%) & 5/7 (71.4\%) & 7/10 (70.0\%) & 5/6 (83.3\%) & $25 / 40(62.5 \%)$ \\
\hline
\end{tabular}


Table 5 Adverse events

\begin{tabular}{|c|c|c|c|c|c|c|}
\hline & Grade1 & Grade2 & Grade3 & Grade4 & All grade & Grade $\geq 3$ \\
\hline Total & $38(83 \%)$ & $18(39 \%)$ & $7(15 \%)$ & - & $41(89 \%)$ & $7(15 \%)$ \\
\hline \multicolumn{7}{|l|}{ Hematologic } \\
\hline Neutropenia & 5 & 4 & 1 & - & $10(22 \%)$ & $1(2 \%)$ \\
\hline Leukocytopenia & 7 & 6 & - & - & $13(28 \%)$ & - \\
\hline Anemia & 13 & 5 & 2 & - & $20(43 \%)$ & $2(4 \%)$ \\
\hline Thrombocytopenia & 6 & 2 & - & - & $8(17 \%)$ & - \\
\hline \multicolumn{7}{|l|}{ Gastrointestinal } \\
\hline Nausea & 9 & 2 & 1 & - & $13(26 \%)$ & $1(2 \%)$ \\
\hline Vomiting & 2 & 0 & 1 & - & $3(7 \%)$ & $1(2 \%)$ \\
\hline Anorexia & 5 & 4 & 2 & - & $11(24 \%)$ & $2(4 \%)$ \\
\hline Diarrhea & 4 & 5 & 2 & - & $11(24 \%)$ & $2(4 \%)$ \\
\hline Abdominal pain & - & - & 1 & - & $1(2 \%)$ & $1(2 \%)$ \\
\hline \multicolumn{7}{|l|}{ Others } \\
\hline Total bilirubin elevation & 4 & - & - & - & $4(9 \%)$ & - \\
\hline AST elevation & 2 & - & - & - & $2(4 \%)$ & - \\
\hline ALT elevation & 1 & - & - & - & $1(2 \%)$ & - \\
\hline Creatinine elevation & 1 & 1 & - & - & $2(4 \%)$ & - \\
\hline Aphthous stomatitis & 3 & 2 & - & - & $5(11 \%)$ & - \\
\hline Fatigue & 11 & 7 & - & - & $18(39 \%)$ & - \\
\hline Pigmentation & 11 & - & - & - & $11(24 \%)$ & - \\
\hline Rash & 3 & 3 & - & - & $6(13 \%)$ & - \\
\hline Chest pain & - & 1 & - & - & $1(2 \%)$ & - \\
\hline
\end{tabular}

Abbreviations: AST aspartate aminotransferase, ALT alanine aminotransferase

available) in colon cancer [20] and $72.2 \%$ (rate for those without recurrence, $75.8 \%$ ) in pancreatic cancer [11]. Compared to other regimens for BTC, the BILCAP trial that evaluated a 6-month administration of capecitabine and the BCAT trial that evaluated a 6-month administration of gemcitabine showed the complete rates were 54.7 and $52.1 \%$, respectively $[9,21]$. In the current study,
65.2\% (those without recurrence, 70.0\%) completed a four-course administration (data were not shown), which seems to be almost acceptable and comparable with other cancers or other regimens.

This study showed a higher incidence of gastrointestinal adverse events compared to that of the phase II trials for unresectable or recurrent BTC [12] and a high

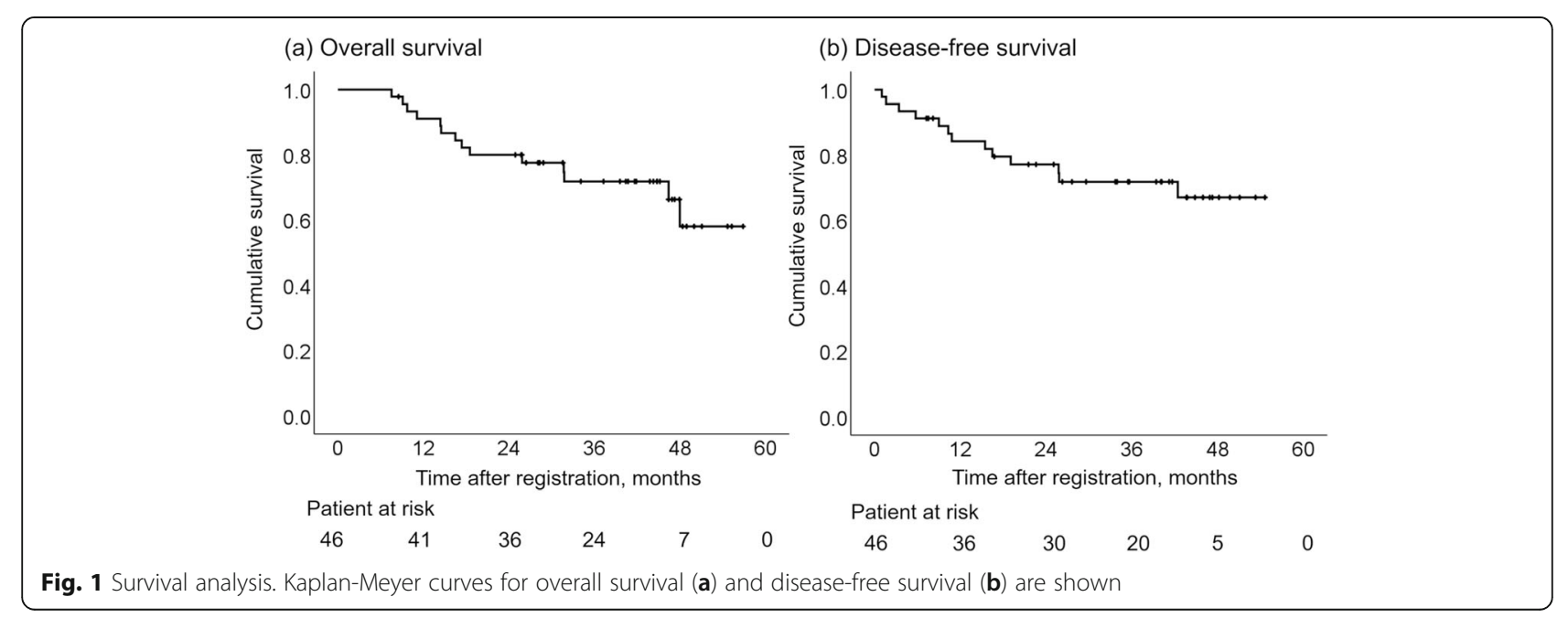


incidence of early discontinuation, especially among elderly patients. Specifically, there were several patients who had their medication discontinued due to refusal following grade 1 or 2 gastrointestinal adverse reactions. The abovementioned findings could be attributed to the influence of surgery. Most of the curative surgeries performed for BTC were extremely invasive with extensive lymph node dissections and upper-gastrointestinal reconstructions such as pancreatoduodenectomy or major hepatectomy with extra bile duct resection. Similar data were reported after gastrectomy or major hepatectomy [19] [13]. In a recent study, older age and prescription by surgeons were reported as risk factors for S-1 discontinuation in gastric cancer [22]. In this study, S-1 was administered by surgeons, which might have caused early discontinuation due to insufficient dose modification or medication for adverse events. Another recent prospective study demonstrated that the completion rate of adjuvant therapy increased with combining Kampo for appetite increase [23]. This result showed the importance of control or prevention of gastrointestinal symptoms in patients who have undergone upper abdominal surgery. Therefore, we suggest prophylactic treatment for gastrointestinal symptoms for older patients or prescription by oncologists to avoid early discontinuation. However, it should be noted only one patient discontinued treatment due to a gastrointestinal adverse event after the second course. These results suggest 1-year administration may be tolerable for patients who can receive administration for 6 months.

The ASCOT trial is evaluating the efficacy of 6month administration of S-1 postoperatively for patients with bile duct cancer [14]. However, the duration was decided according to the adjuvant therapy regimen for pancreatic cancer [11]. There was no evidence regarding the duration of administration. Rather, in a non-inferiority study comparing the 1-year administration of S-1 with a 6-month administration for gastric cancer, the 1-year administration group had better prognosis in the interim analysis. Thus, 1-year administration is still the standard for gastric cancer treatment [15]. Our study showed nearly $80 \%$ of 2 -year recurrentfree survival. This result seems promising, although this cohort included more than $40 \%$ of patients with positive lymph nodes, which is a common poor prognostic factor in BTC as referred to in Japanese registry data or other clinical trials $[4,9,13,16]$. Because our results about feasibility and prognosis were acceptable, we started a prospective randomized controlled trial in 2018 to evaluate the efficacy of 1-year administration of S-1 as adjuvant chemotherapy by comparing that of 6months administration of S-1 (TOSBIC-03 trial UMIN: 000029421) for adjuvant therapy of BTC. We are expecting that this study will show a significant survival benefit for 1-year administration with high completion rate and that the 1-year administration of S-1 could be one of the standard treatments after curative surgery for BTC.

\section{Conclusion}

The 1-year administration of adjuvant S-1 therapy for resected BTC was feasible. This regimen has a potential to become a promising treatment for resected BTC.

\section{Supplementary information}

Supplementary information accompanies this paper at https://doi.org/10. 1186/s12885-020-07185-6.

Additional file 1: Table S1. Univariate analysis for early discontinuation (within 2 courses)

Additional file 2. The list of ethics committees and the reference number

\section{Abbreviations}

BTC: Biliary tract cancer; DFS: Disease-free survival; OS: Overall survival; RCT: Randomized control trial; ECOG-PS: Eastern Cooperative Oncology Group Performance Status; AST: Aspartate aminotransferase; ALT: Alanine aminotransferase; GFR: Glomerular filtration rate; RDI: Relative dose intensity; Cl: Confidence interval; CEA: Carcinoembryonic antigen; CA19-

9: Carbohydrate antigen 19-9

\section{Acknowledgements}

We appreciated to the following additional investigators for their contributions to this trial: Masayuki Kojima, Yutaka Takigawa, Yoshinori Hoshino, Takashi Ishida, Mutsuhito Matsuda, Masanori Odaira, Koji Osumi, Satoshi Tabuchi, Yusuke Katsuki., Tomonori Fujimura.

\section{Authors' contributions}

Ol conceived the study. OI, TM, MS, MK, YA, HY, GO and SH designed the study. YT, NK, ET, HS, KI, HU, SE, SH, KS, TS, MI, MS, KA, HF, KT and JM managed this study and collected data in each institute. KY oversaw the study, OI and YT carried out data analyses, interpreted data and drafted the manuscript; all authors reviewed and approved the final version of the manuscript.

\section{Funding}

We have no funding to declare.

Availability of data and materials

The protocol and the datasets are available from the corresponding author on reasonable request.

\section{Ethics approval and consent to participate}

This study was approved by the ethics committee of Keio University School of Medicine (\#20110027), and also approved by the other institutional review board in all participating institutes. They were listed in Additional file 2. The research met the standards of the Declaration of Helsinki. The forms of informed consent were written by all participants.

Consent for publication

Not applicable.

\section{Competing interests}

Y. Kitagawa and M. Shinoda received designated donation for research funding from Taiho Pharmaceutical. Y. Kitagawa and O. Itano has an endowed chair of Taiho Pharmaceutical. Other authors have no conflict of interest.

\section{Author details}

${ }^{1}$ Department of Surgery, Keio University School of Medicine, Tokyo, Japan. ${ }^{2}$ Department of Hepato-Biliary-Pancreatic and Gastrointestinal Surgery, 
International University of Health and Welfare School of Medicine, 4-3, Kozunomori, Narita-shi, Chiba 286-8686, Japan. ${ }^{3}$ Department of Surgery, Japanese Red Cross Ashikaga Hospital, Tochigi, Japan. ${ }^{4}$ Department of Surgery, Machida Keisen Hospital, Tokyo, Japan. ${ }^{5}$ Department of Surgery, Saiseikai Utsunomiya Hospital, Tochigi, Japan. ${ }^{6}$ Department of Surgery, Sano Kousei General Hospital, Tochigi, Japan. 'Department of Surgery, National Hospital Organization Tokyo Medical Center, Tokyo, Japan. ${ }^{8}$ Department of Surgery, Eiju General Hospital, Tokyo, Japan. ${ }^{9}$ Department of Surgery, National Hospital Organization Saitama National Hospital, Saitama, Japan. ${ }^{10}$ Department of Surgery, National Hospital Organization Tochigi Medical Center, Tochigi, Japan. "'Department of Surgery, Tama Kyuryo Hospital, Tokyo, Japan. ${ }^{12}$ Department of Surgery, Fussa Hospital, Tokyo, Japan. ${ }^{13}$ Department of Surgery, Kawasaki Municipal Kawasaki Hospital, Kanagawa, Japan. ${ }^{14}$ Department of Surgery, Hiratsuka City Hospital, Kanagawa, Japan. ${ }^{15}$ Department of Surgery, Tokyo Dental College Ichikawa General Hospital, Chiba, Japan. ${ }^{16}$ Department of Surgery, Saitama City Hospital, Saitama, Japan.

Received: 12 April 2020 Accepted: 15 July 2020

Published online: 23 July 2020

\section{References}

1. Patel T. Worldwide trends in mortality from biliary tract malignancies. BMC Cancer. 2002;2:10.

2. Jemal A, Bray F, Center MM, Ferlay J, Ward E, Forman D. Global cancer statistics. CA Cancer J Clin. 2011;61:69-90.

3. Fitzmaurice C, Akinyemiju TF, Al Lami FH, Alam T, Alizadeh-Navaei R, Allen C, et al. Global, regional, and National Cancer Incidence, mortality, years of life lost, years lived with disability, and disability-adjusted life-years for 29 Cancer groups, 1990 to 2016: a systematic analysis for the global burden of disease study. JAMA Oncol. 2018:4:1553-68.

4. Ishihara S, Horiguchi A, Miyakawa S, Endo I, Miyazaki M, Takada T. Biliary tract cancer registry in Japan from 2008 to 2013. J Hepatobiliary Pancreat Sci. 2016;23:149-57.

5. Kudo M, Izumi N, Ichida T, Ku Y, Kokudo N, Sakamoto M, et al. Report of the 19th follow-up survey of primary liver cancer in Japan. Hepatol Res. 2016;46: 372-90.

6. Horgan AM, Amir E, Walter T, Knox JJ. Adjuvant therapy in the treatment of biliary tract cancer: a systematic review and meta-analysis. J Clin Oncol. 2012;30:1934-40.

7. Neoptolemos JP, Moore MJ, Cox TF, Valle JW, Palmer DH, McDonald AC, et al. Effect of adjuvant chemotherapy with fluorouracil plus Folinic acid or gemcitabine vs observation on survival in patients with resected Periampullary adenocarcinoma: the ESPAC-3 Periampullary Cancer randomized trial. JAMA. 2012;308:147-56.

8. Takada T, Nimura Y, Katoh H, Nagakawa T, Nakayama T, Matsushiro T, et al. Prospective randomized trial of 5-fluorouracil, doxorubicin, and mitomycin C for non-resectable pancreatic and biliary carcinoma: multicenter randomized trial. Hepatogastroenterology. 1998:45:2020-6.

9. Primrose JN, Fox RP, Palmer DH, Malik HZ, Prasad R, Mirza D, et al. Capecitabine compared with observation in resected biliary tract cancer (BILCAP): a randomised, controlled, multicentre, phase 3 study. Lancet Oncol. 2019;20:663-73.

10. Sakuramoto S, Sasako M, Yamaguchi T, Kinoshita T, Fujii M, Nashimoto A, et al. Adjuvant chemotherapy for gastric Cancer with S-1, an Oral Fluoropyrimidine. N Engl J Med. 2007;357:1810-20.

11. Uesaka K, Boku N, Fukutomi A, Okamura Y, Konishi M, Matsumoto I, et al. Adjuvant chemotherapy of S-1 versus gemcitabine for resected pancreatic cancer: a phase 3, open-label, randomised, non-inferiority trial (JASPAC 01). Lancet. 2016;388:248-57.

12. Furuse J, Okusaka T, Boku N, Ohkawa S, Sawaki A, Masumoto T, et al. S-1 monotherapy as first-line treatment in patients with advanced biliary tract cancer: a multicenter phase II study. Cancer Chemother Pharmacol. 2008;62: 849-55.

13. Kobayashi S, Nagano H, Tomokuni A, Gotoh K, Sakai D, Hatano E, et al. A prospective, randomized phase II study of adjuvant gemcitabine versus S-1 after major hepatectomy for biliary tract Cancer (KHBO 1208): Kansai Hepato-biliary oncology group. Ann Surg. 2019;270:230-7.

14. Nakachi K, Konishi M, Ikeda M, Mizusawa J, Eba J, Okusaka T, et al. A randomized phase III trial of adjuvant S-1 therapy vs. observation alone in resected biliary tract cancer: Japan clinical oncology group study (JCOG1202, ASCOT). Jpn J Clin Oncol. 2018;48:392-5.
15. Yoshikawa T, Terashima M, Mizusawa J, Nunobe S, Nishida Y, Yamada T, et al. Four courses versus eight courses of adjuvant S-1 for patients with stage II gastric cancer (JCOG1104 [OPAS-1]): an open-label, phase 3, noninferiority, randomised trial. Lancet Gastroenterol Hepatol. 2019;4:208-16.

16. Nakachi K, Konishi M, Ikeda M, Shimada K, Okusaka T, Saiura A, et al. Feasibility study of postoperative adjuvant chemotherapy with S-1 in patients with biliary tract cancer. Int J Clin Oncol. 2018;23:894-9.

17. Bosman FT, Carneiro F, Ralph HH, Theise ND. World Health Organization classification of Tumours of the digestive system. Lyon: IARC; 2010.

18. Brierley J, Gospodarowicz M, Wittekind C. TNM classification of malignant tumours. 8th ed. New York: Wiley-Blackwell; 2016.

19. Kinoshita T, Nashimoto A, Yamamura Y, Okamura T, Sasako M, Sakamoto J, et al. Feasibility study of adjuvant chemotherapy with S-1 (TS-1; tegafur, gimeracil, oteracil potassium) for gastric cancer. Gastric Cancer. 2004;7:104-9.

20. Kusumoto $T$, Ishiguro $M$, Nakatani $E$, Yoshida $M$, Inoue $T$, Nakamoto $Y$, et al. Updated 5-year survival and exploratory Tx N subset analyses of ACTS-CC trial: a randomised controlled trial of S-1 versus tegafur-uracil/leucovorin as adjuvant chemotherapy for stage III colon cancer. ESMO Open. 2018;3: e000428.

21. Ebata T, Hirano S, Konishi M, Uesaka K, Tsuchiya Y, Ohtsuka M, et al. Randomized clinical trial of adjuvant gemcitabine chemotherapy versus observation in resected bile duct cancer. Br J Surg. 2018;105:192-202.

22. Kano Y, Ohashi M, Hiki N, Takahari D, Chin K, Yamaguchi K, et al. Facilitated completion of 1-year adjuvant S-1 monotherapy for pathological stage II or III gastric cancer by medical oncologists. Surg Today. 2020. https://doi.org/ 10.1007/s00595-020-01995-8.

23. Okabe H, Kinjo Y, Obama K, Hosogi H, Hata H, Asao Y, et al. A randomized phase II study of s-1 adjuvant chemotherapy with or without hochu-ekki-to, a japanese herbal medicine, for stage II/II gastric cancer: the kugc07 (shot) trial. Front Oncol. 2019;9:294

\section{Publisher's Note}

Springer Nature remains neutral with regard to jurisdictional claims in published maps and institutional affiliations.

Ready to submit your research? Choose BMC and benefit from:

- fast, convenient online submission

- thorough peer review by experienced researchers in your field

- rapid publication on acceptance

- support for research data, including large and complex data types

- gold Open Access which fosters wider collaboration and increased citations

- maximum visibility for your research: over $100 \mathrm{M}$ website views per year

At $\mathrm{BMC}$, research is always in progress.

Learn more biomedcentral.com/submissions 